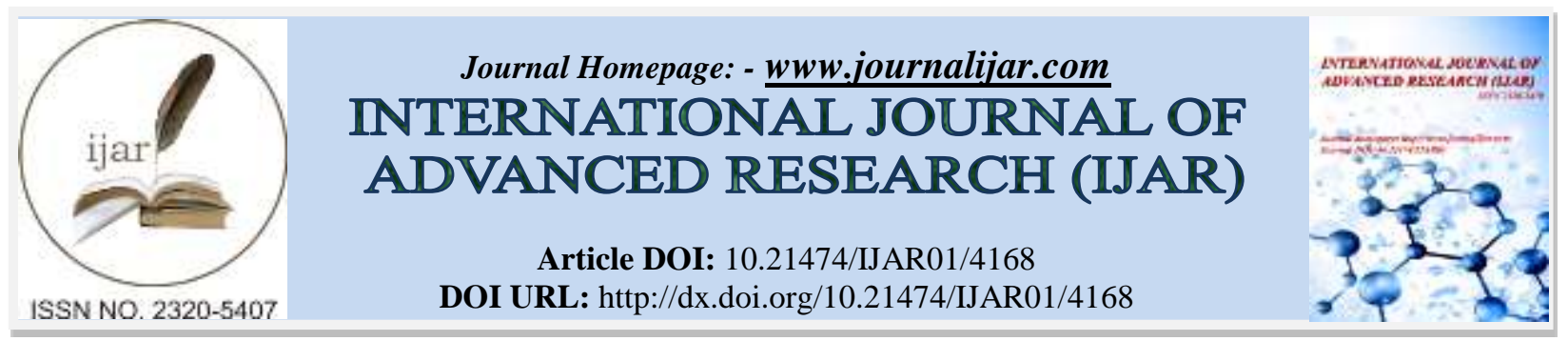

RESEARCH ARTICLE

\title{
OUR EXPERIENCE IN ULTRASOUND GUIDED SALINE REDUCTION IN CHILDHOOD INTUSSUSCEPTION.
}

\author{
J.Muthukumaran MBBS, DLO, MS, MCh ${ }^{1}$, D. Vembar MBBS, MS, $\mathrm{MCh}^{2}$, V.Gomathi MBBS, MS, $\mathrm{MCh}^{2}$ \\ and P.Praveen MBBS, DNB, MCh Resident ${ }^{3}$. \\ 1. Professor and HOD, Department of Pediatric Surgery, Institute of Child Health, Chennai, India. \\ 2. Assistant Professor, Department of Pediatric Surgery, Institute of Child Health, Chennai, India \\ 3. Department of Pediatric Surgery, Institute of Child Health, Chennai, India.
}

\section{Manuscript Info}

[.........................

Manuscript History

Received: 17 March 2017

Final Accepted: 14 April 2017

Published: May 2017

\section{Abstract}

To study the feasibility and efficacy of ultrasound guided saline reduction of acute intussusception in children who present early. Materials and Methods: Thirty five children with intussusception were subjected to saline reduction. Results: Of the thirty five patients who underwent this procedure, all had complete reduction of ileo-colic intussusception. Two had recurrence after total reduction and rereduction failed. The patients then underwent laparotomy . Conclusion: Ultrasound guided saline reduction for childhood intussusception is safe and may be an effective alternative method in the non-operative management of intussusception.

Copy Right, IJAR, 2016,. All rights reserved.

\section{Introduction:-}

Intussusception is a common abdominal emergency in infants and children. A lot of debate exists regarding the best method for diagnosis and treatment. In our set up, most children with intussusception come to us late and only a few satisfy the criteria for non-operative hydrostatic reduction. Whenever hydrostatic reduction of intussusception is feasible, barium enema has been considered the gold standard. However recently, alternative methods using air [1], oxygen [2] and ionic water soluble iodinated contrast media [3] have been reported.

As the diagnosis of intussusception can be easily made out by ultrasound, we tried hydrostatic reduction of childhood intussusception using water under US guidance, with the idea of reducing exposure to radiation, lessening absorption of radiation by the contrast media and decreasing potential peritoneal contamination in the event of iatrogenic perforation during attempted reduction

\section{Materials and Methods:-}

In 2016, 50 patients in the age group of three months to 11 years presented to us with signs and symptoms suggestive of intussusception of which 32 were boys and 18 were girls. US guided saline reduction was attempted in 35 of these patients. Only those patients who did not have signs of peritonitis, perforation and/or shock were taken up for hydrostatic reduction. The diagnosis was made by visualization of a doughnut or target-shaped mass on transverse images (hypoechoic edematous bowel surrounding a central area of increased echogenicity) and a pseudo-kidney appearance on the longitudinal images. 
The technique of ultrasound guided saline reduction used by us was the same as that for conventional hydrostatic barium reduction, in which barium and fluoroscopy were replaced by water and real-time ultrasonography. All US examinations were performed with a $5-\mathrm{MHz}$ curvilinear pediatric probe (Hitachi, Japan). The reduction was attempted with the reservoir at a height of 4-5 feet (equivalent to $90-110 \mathrm{~mm}$ of $\mathrm{Hg}$ ) above the table, occasionally taking it upto 5.75 feet (equivalent to $130 \mathrm{~mm}$ of $\mathrm{Hg}$ ) to achieve the maximum pressure. (A 1-foot saline column is equivalent to a $22.6 \mathrm{~mm} \mathrm{Hg}$ column. The pressure values at the distal end of the rectal tube were calculated by multiplying the total length of the water column by its specific gravity i.e. 1). Through an appropriately sized Foley's catheter 500 to $1000 \mathrm{ml}$ of saline under US control. The intussusceptum was observed to move backward gradually to the ileocecal region with increasing pressure. The procedure was continued till the intussusceptum disappeared completely and the distal ileum was filled with water.

\section{The four distinct findings on US suggesting successful reduction were:-}

$>$ Disappearance of the intussusceptum,

$>$ Visualisation of reflux of water and air bubbles through the cecum and ascending colon into the ileum through the ileocecal valve

$>$ Demonstration of water distended ileum and

$>$ Absence of intussusceptum noted during the post-evacuation US examination.

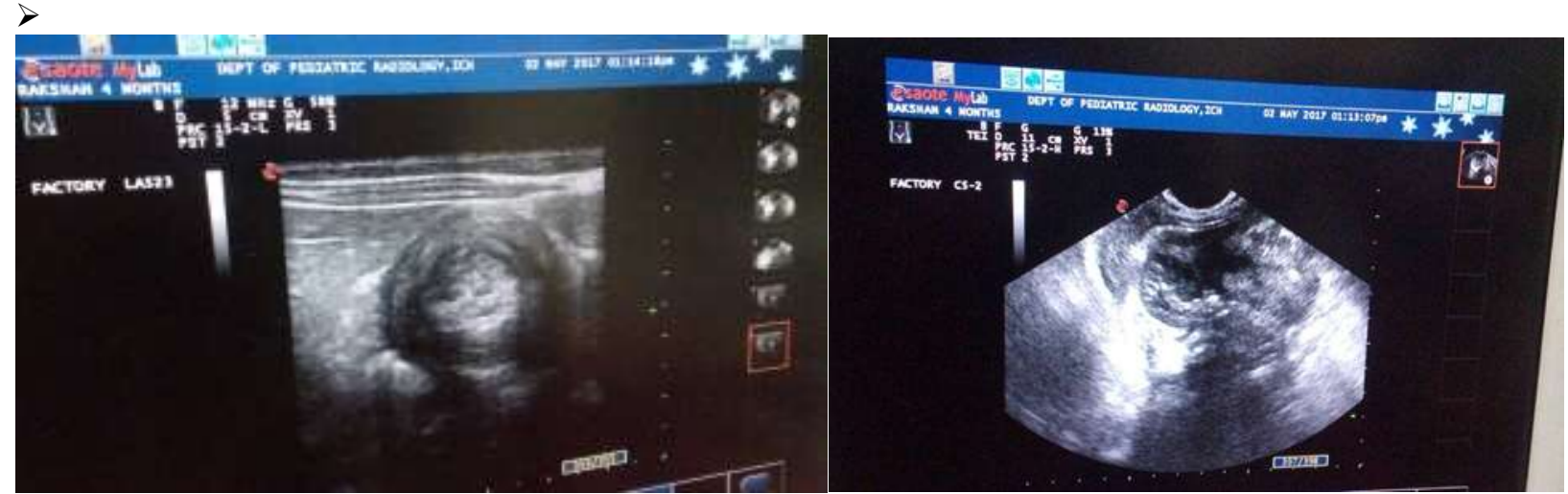

(target sign in ultrasound)

(ultrasound image after saline reduction)

Once reduction was complete, the saline was evacuated from the colon and the abdomen was re-examined to determine whether there was any residual lesion or recurrence of intussusception. Usually one or two attempts each lasting 5-10 minutes were needed. After successful reduction, the patients were discharged only when they tolerated a regular diet and had normal bowel movement.

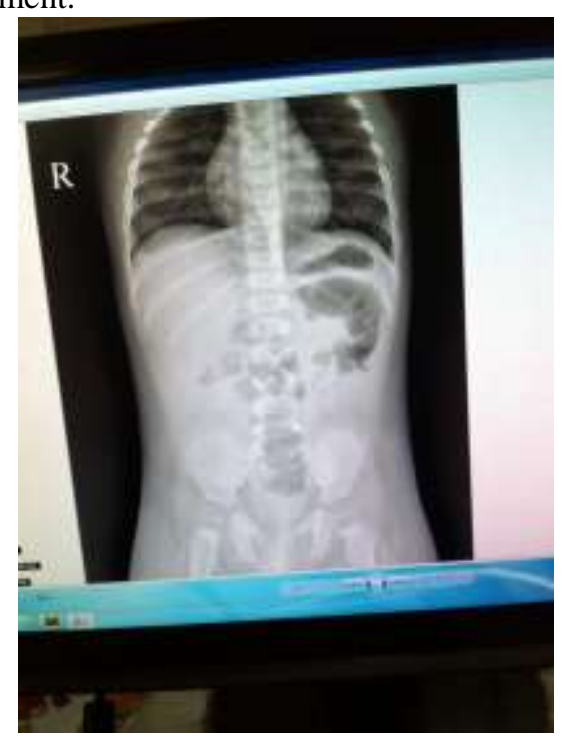

(colon cut off sign in $\mathrm{x}$ ray abdomen) 


\section{Results:-}

Thirty five patients were subjected saline reduction of the intussusception. Complete reduction was possible in all 35 patients. Two had recurrence after total reduction and re-reduction by saline reduction failed. The patients then underwent laparotomy with findings of a partially reduced ceco-colic intussusception for which manual reduction was done. None of the patients had any complications during or after hydrostatic reduction.

\section{Discussion:-}

Intussusception is a common cause of intestinal obstruction in infancy and early childhood. Use of an enema for nonsurgical reduction of ileocolic intussusception in infants and children was initiated more than 80 years ago [4],[5]. For a long time, the enema was given only under general clinical and local palpatory guidance. Reports on pressure and fluoroscopy-guided methods did not start appearing until 40 years ago. In Western countries, the main contrast media used for this procedure were barium sulfate suspension and, later, water-soluble contrast medium mixtures [6],[7]. Rectal insufflation of air is preferred in China and Argentina, where intussusception is particularly frequent [8],[9]. The use of air or oxygen to reduce intussusception was accepted in North America and Europe a little more than 10 years ago [10],[11].

The initial management of intussusception has changed and new methods are being continuously investigated to avoid radiation exposure and barium peritonitis. Hydrostatic reduction under US guidance was first described by Kim et al in 1982 [12].

The first large series comprising of 377 children treated with this methodology was reported in 1988 [13]. The technique of saline reduction is essentially the same as that for conventional hydrostatic barium reduction, with barium and fluoroscopy replaced by water and real-time US. The use of color Doppler US has also been reported recently [14],[15].

Many workers prefer to use a combination of Ringer lactate/saline with a water soluble contrast medium, so that sonographic reduction is quickly reconfirmed by a short fluoroscopic and radiographic documentation. The fluoroscopic confirmation does not significantly add to radiation doses but on the contrary raises one's confidence levels significantly [16].

Unlike the patients seen in developed countries, many of our patients display clinical and/or radiologic contraindications to non-surgical reduction. The absolute contraindications to hydrostatic reduction are:-

Severe dehydration

Marked abdominal distension

Clinical features of peritonitis or demonstration of free intraperitoneal air on a plain abdominal radiograph.

\section{Relative contraindications Are:-}

History longer than 48 hours

Extremes of age - patient less than three months of age or more than two years

Dehydration more than five percent.

Small bowel obstruction on plain radiographs [12],[17]

US demonstration of a thick irregular rim of the target measuring more than $10 \mathrm{~mm}$ [18],

Absent Doppler signal on a color Doppler signifying non-viable bowel [15].

Ultrasonic demonstration of a lead point [19].

The advantages of using saline reduction for reduction of intussusception are:-

There is no risk of $\mathrm{x}$-ray exposure.

It can trace the change of the mass closely, both on transverse and longitudinal scans and can provide a clear echogram: definite criteria of reduction can be obtained.

Ileo-ileo-colic intussusception can be diagnosed during reduction.

The reduction process can be directly watched in a lit room and at the same time changes in the child's general condition, including breathing and abdominal distension can also be assessed.

Intestinal perforation during reduction can be accurately and promptly recognised, when the management is simple, reliable and safe.

In cases where partial reduction is achieved, the operating time is markedly reduced. 


\section{Conclusion:-}

Acute intussusception is a surgical disease managed by the pediatric surgeon and radiologist as a team. We believe that with more experience in the use of saline reduction for reduction of intussusception, we will be able to avoid the use of barium. Saline reduction is an effective alternative method of non-operative treatment of childhood intussusception.

\section{References:-}

1. Fiorito ES, Cuestas LAR. Diagnosis and treatment of acute intestinal intussusception with controlled insufflation of air. Pediatrics 1959; 24: 241-244. Back to cited text no. 1

2. Phelan E, DeCampo JF, Malechy G. Comparison of oxygen and barium reduction of ileo-colic intussusception. AJR 1988; 150: 1349-1352. Back to cited text no. 2

3. Kuha AJ, Benator AM. Intussusception: Hydrostatic pressure equivalents for barium and meglumine sodium diatrizoate. Radiology 1990; 175: 125-126. Back to cited text no. 3

4. Finkelstein H. Lehrbuch der sauglingskrankheiten. Zweite halfte, abteilung 1, Berlin, Germany, Fischer's Medicin, 1908, pp 155-157. Back to cited text no. 4

5. Heubner O. Lehrbuch der kinder-heikunde. Erster band. Leipzig, Germany; JA Barth, 1906, pp 219-223. Back to cited text no. 5

6. Katz ME, Kohn P. Intussusception reduction 1991: an International survey of Pediatric Radiologists. Pediatr Radiol 1992; 22: 318-322. Back to cited text no. 6

7. Meyer JS. The current radiologic management of intussusception: a survey and review. Pediatr Radiol 1992; 22: 322-325. Back to cited text no. 7

8. Guo J, Ma X, Zhou Q. Results of air pressure enema reduction of intussusception: 6369 cases in 13 years. J Pediatr Surg 1986; 21: 1201-1203. Back to cited text no. 8

9. Jinzhe Z, Yenxia W, Linchi W. Rectal insuflation reduction of intussusception in infants. J Pediatr Surg 1986; 21: 30-32. Back to cited text no. 9

10. de Campo JF, Phelan E. Gas reduction of intussusception. Pediatr Radiol 1989; 19: 297-298. Back to cited text no. 10

11. Gu L, Alton DJ, Daneman A, et al . Intussusception reduction in children by rectal insufflation of air. AJR 1988; 150: 1345-1348. Back to cited text no. 11

12. Kim YG, Choi BI, Yeon KM, et al . Diagnosis and treatment of childhood intussusception using real time ultrasonography and saline enema. Preliminary report. J Korean Soc Med Ultrasound 1982; 1: 66-70. Back to cited text no. 12

13. Wang GD, Liu SJ: Enema reduction of intussusception by hydrostatic pressure under ultrasound guidance. J Pediat Surg 1988; 23: 814-818. Back to cited text no. 13

14. Lam AH, Firman K: Value of US including colour Doppler in the diagnosis and management of long standing intussusception. Pediatr Radiol 1992; 22: 112-114. Back to cited text no. 14

15. Lim HK, Bae SH, Lee KH, Seo GS, Yoon GS: Assessment of reducibility of ileocolic intussusception in children: usefulness of colour doppler sonography. Radiology 1994; 191: 781-785. Back to cited text no. 15

16. Riebel TW, Nasir R, Weber K: US-guided hydrostatic reduction of intussusception in children. Radiology 1993; 188: 513-516. Back to cited text no. 16

17. Battenay F, Beasley SW, De Campo JF et al : Intussusception: clinical prediction of outcome of barium reduction. Aust NZ J Surg 1988; 58: 899-902. Back to cited text no. 17

18. Pracros JP, Tran-Minh VA, Morin DE, et al : Acute intestinal intussusception in children: contribution of ultrasonography (145 cases). Ann Radiol 1987; 30: 525-530. Back to cited text no. 18

19. Stringer MD, Capps SW, Pablot SM: Sonographic detection of the lead point in intussusception. Arch Dis Child 1992; 67: 529-530. 